\title{
Investigation of four Carbon Monoxide isotopomers in natural abundance by laser induced fluorescence in a supersonic jet
}

$\underline{\text { Anton du Plessis }}$

CSIR National Laser Centre, PO Box 395, Pretoria, 0001

Erich G Rohwer

Laser Research Institute, Department of Physics, University of Stellenbosch, Private

Bag X1, Matieland, 7602

Christine M Steenkamp

Laser Research Institute, Department of Physics, University of Stellenbosch, Private

Bag X1, Matieland, 7602

Corresponding author:

Anton du Plessis

CSIR National Laser Centre, Building 46a, PO Box 395, Pretoria, 0001

Telephone: +27128414504

Mobile: +27844747110

Fax: +27128413152

Email: adplessis2@,csir.co.za 


\begin{abstract}
The four Carbon Monoxide (CO) isotopomers ${ }^{12} \mathrm{C}^{16} \mathrm{O},{ }^{13} \mathrm{C}^{16} \mathrm{O},{ }^{12} \mathrm{C}^{18} \mathrm{O}$ and ${ }^{12} \mathrm{C}^{17} \mathrm{O}$ have been detected simultaneously in a CO gas sample of natural isotopic abundance by measuring rovibronic excitation spectra of 6 vibronic bands in the Fourth Positive System. The CO sample was flow cooled by adiabatic expansion in a pulsed supersonic jet. The rovibronic excitation spectra were obtained using a novel pulsed laser source (pulse duration $\sim 25 \mathrm{~ns}$, spectral bandwidth $\sim 5 \mathrm{GHz}$ ) continuously tunable in the 139 - $155 \mathrm{~nm}$ vacuum ultraviolet wavelength region for excitation and recording the total fluorescence. In the present paper we report on the spectroscopic results obtained, including transition wavelengths of three forbidden rovibronic bands $\left(\mathrm{e}^{3} \Sigma^{-}-\mathrm{X}^{1} \Sigma^{+}(1,0), \mathrm{d}^{3} \Delta^{-} \mathrm{X}^{1} \Sigma^{+}(5,0), \mathrm{a}^{3} \Sigma^{+}-\mathrm{X}^{1} \Sigma^{+}(14,0)\right)$ of ${ }^{12} \mathrm{C}^{16} \mathrm{O}$ and band origins of six rovibronic bands $\left(\mathrm{A}^{1} \Pi\left(\mathrm{v}^{\prime}=0-5\right)-\mathrm{X}^{1} \Sigma^{+}\left(\mathrm{v}^{\prime}{ }^{\prime}=0\right)\right)$ of the rare isotopomer ${ }^{12} \mathrm{C}^{17} \mathrm{O}$, and on the experimental conditions facilitating the high sensitivity of the measurements. The exceptional sensitivity demonstrated by the results has been achieved by fine tuning experimental conditions including the conditions in the supersonic expansion, the jet pulse duration and the laser pulse timing.
\end{abstract}

Keywords: Carbon Monoxide, Isotopomer, Fourth Positive System, Experimental conditions, Forbidden transitions, Supersonic jet, Laser induced fluorescence, Vacuum Ultraviolet 


\section{Introduction}

Carbon Monoxide (CO) is important as a prototype diatomic molecule and as a tracer in the study of chemical and physical processes. The spectroscopic study of the rare isotopomers and weak forbidden transitions of $\mathrm{CO}$ is strongly motivated by the particular significance of these molecules as tracers in astrophysical research. Not only is $\mathrm{CO}$ the second most abundant molecular species in the interstellar space [1], but the distribution and isotopic fractionation of $\mathrm{CO}$ in the interstellar gas clouds and stellar envelopes yield important parameters in models of stellar evolution and chemistry [2]. The vacuum ultraviolet (VUV) spectrum of CO in the interstellar space has been made accessible by satellite based spectrographs, such as on the Hubble Space Telescope [3].

The $\mathrm{A}^{1} \Pi-\mathrm{X}^{1} \Sigma^{+}\left(\mathrm{v}^{\prime}, \mathrm{v}^{\prime \prime}\right)$ electronic band system (Fourth Positive System) of CO is a dominant feature in the astrophysically observed VUV spectra and accurate laboratory wavelength data for these spectral lines are required. The relevant data for the ${ }^{12} \mathrm{C}^{16} \mathrm{O}$, ${ }^{13} \mathrm{C}^{16} \mathrm{O}$ and ${ }^{12} \mathrm{C}^{18} \mathrm{O}$ isotopomers are available [4,5], having been obtained from laboratory measurements - in the case of ${ }^{12} \mathrm{C}^{18} \mathrm{O}$ using isotope enriched samples.

We have developed a laser-induced fluorescence excitation spectroscopy experiment to investigate the VUV spectrum of $\mathrm{CO}$, with the aim of obtaining the ${ }^{12} \mathrm{C}^{17} \mathrm{O}$ spectrum ( $0.04 \%$ natural abundance) and the forbidden singlet-triplet transitions of ${ }^{12} \mathrm{C}^{16} \mathrm{O}$ in this wavelength range. The transition wavelengths obtained in this study for ${ }^{12} \mathrm{C}^{17} \mathrm{O}$ and the application of this data to astrophysical calculations has been published recently [6].

The present paper describes the experimental conditions and methods that facilitated the investigation of the $\mathrm{A}^{1} \Pi-\mathrm{X}^{1} \Sigma^{+}\left(\mathrm{v}^{\prime}, \mathrm{v}^{\prime \prime}\right)$ system of ${ }^{12} \mathrm{C}^{16} \mathrm{O},{ }^{13} \mathrm{C}^{16} \mathrm{O},{ }^{12} \mathrm{C}^{17} \mathrm{O}$ and 
${ }^{12} \mathrm{C}^{18} \mathrm{O}$ simultaneously in natural abundance. The challenge in this work is to detect weak lines and improve their signal-to-noise ratio among strong neighbouring ${ }^{12} \mathrm{C}^{16} \mathrm{O}$ lines. The specific conditions that facilitated this sensitivity are presented here for the first time and may be used in similar experiments to obtain high sensitivity for lowabundance isotopomers. New results presented in this paper include the wavelength data of forbidden singlet-triplet transitions of ${ }^{12} \mathrm{C}^{16} \mathrm{O}$ observed during the course of this study, of which 10 have not been measured before, as well as ${ }^{12} \mathrm{C}^{17} \mathrm{O}$ band origins of 6 vibronic bands obtained from our measurements.

\section{Experimental setup}

The experimental setup is shown in Figure 1. The details of the instrumentation used in the setup has been described elsewhere $[7,8,9]$ and will not be repeated here. Two pulsed dye laser beams are combined in a magnesium vapour krypton gas medium to generate vacuum ultraviolet (VUV) laser radiation by a two-photon resonant fourwave sum frequency mixing process. The medium is prepared in a heat pipe oven. This narrow bandwidth tunable VUV radiation (pulse duration $\sim 25 \mathrm{~ns}$, spectral bandwidth $\sim 5 \mathrm{GHz}$ ) is used to excite individual rovibronic transitions of $\mathrm{CO}$. A pulsed supersonic expansion regulated by a solenoid valve (General Valves, Series 9) driven by a pulse driver (Iota One, General Valve Corporation) is used to introduce the sample gas in natural isotopic abundance and at low temperature. The laser and gas pulses are synchronized by using an electronic delay generator (Stanford Research Systems, DG535).

A solar-blind photomultiplier tube (PMT1) measures the fluorescence from the intersection of the gas and laser pulses, while a second solar-blind photomultiplier tube (PMT2) measures the transmitted VUV laser signal. The transmitted laser is sent through a monochromator (McPherson, model 218) for selection of the VUV 
wavelength of interest, thereby improving the signal-to-noise ratio of this measurement. The signal from each photomultiplier is integrated over the laser pulse duration using a boxcar gated integrator (Stanford Research Systems, SR250) and digitized. The data acquisition and the scanning of the VUV wavelength and the delay between the laser and gas pulses are controlled by custom software on a computer. By measuring the laser induced fluorescence (LIF) and transmitted VUV intensity as a function of excitation wavelength, simultaneous LIF and absorption spectra are recorded (termed wavelength scans). A delay scan is obtained by keeping the wavelength tuned to a spectral line and observing the LIF and absorption signals as a function of the temporal delay between gas and laser pulses.

\section{Results and discussion}

\subsection{Typical spectra}

Rovibronic excitation spectra of the $\mathrm{A}^{1} \Pi-\mathrm{X}^{1} \Sigma^{+}\left(\mathrm{v}^{\prime}=0-5, \mathrm{v}^{\prime \prime}=0\right)$ bands of ${ }^{12} \mathrm{C}^{16} \mathrm{O}$, ${ }^{13} \mathrm{C}^{16} \mathrm{O},{ }^{12} \mathrm{C}^{17} \mathrm{O}$ and ${ }^{12} \mathrm{C}^{18} \mathrm{O}$ were obtained simultaneously using both LIF and absorption. The details of the LIF spectra have been reported elsewhere [6], but a description of the band structure is warranted here. The cooling in the supersonic expansion has the effect of simplifying the spectra, since the lowest-J lines have the highest intensities. This effect, in combination with the relatively high sample density in the interaction region, increases the sensitivity of this measurement for the low-J lines, as compared to room-temperature measurements.

As an example of a typical vibronic band, the $\mathrm{A}^{1} \Pi-\mathrm{X}^{1} \Sigma^{+}\left(\mathrm{v}^{\prime}=1, \mathrm{v}{ }^{\prime \prime}=0\right)$ band is shown in Figure 2 in both LIF (lower trace) and absorption (upper trace). The positions of the lowest-J lines of ${ }^{12} \mathrm{C}^{16} \mathrm{O}$ and ${ }^{13} \mathrm{C}^{16} \mathrm{O}$ are indicated, as well as the positions of the $\mathrm{R}(0)$, 
$\mathrm{R}(1)$ and $\mathrm{Q}(1)$ lines of ${ }^{12} \mathrm{C}^{17} \mathrm{O}$ and ${ }^{12} \mathrm{C}^{18} \mathrm{O}$. The difference between the LIF and absorption spectra is clearly visible in the figure.

In the absorption spectrum more ${ }^{12} \mathrm{C}^{16} \mathrm{O}$ lines (especially higher-J lines) are identified and fewer lines of the rarer isotopomers are observed. This can be explained by the larger interaction volume contributing to the total absorption measurement, in contrast to the small cold central volume of the expansion contributing to the LIF measurement. From the dominance of the higher-J lines in the absorption spectrum it is deduced that the higher temperature gas present in the outer parts of the expansion and in the background gas in the vacuum chamber contribute significantly to the absorption measurement. Secondly the signal to noise ratio of the LIF spectrum is much higher than that of the absorption spectrum, due to the practically zero background signal.

The wavelength scales of the measured spectra were calibrated using wavelengths of ${ }^{12} \mathrm{C}^{16} \mathrm{O}$ and ${ }^{13} \mathrm{C}^{16} \mathrm{O}$ lines from literature [4] and a first order calibration function. The detail of the calibration procedure is discussed elsewhere [6]. The average wavelength uncertainty of the measurements over all rovibronic bands is $0.17 \mathrm{pm}$. This uncertainty is comparable to the measured linewidths, which are limited by the laser bandwidth.

In order to illustrate the identification of the rare isotopomer lines, the wavelength region of the LIF spectrum containing the ${ }^{12} \mathrm{C}^{17} \mathrm{O}$ lines in this band is enlarged in Figure 3. In this figure, the positions of ${ }^{12} \mathrm{C}^{16} \mathrm{O},{ }^{12} \mathrm{C}^{17} \mathrm{O}$ and ${ }^{13} \mathrm{C}^{16} \mathrm{O}$ lines are indicated. In this spectrum, five lines of ${ }^{12} \mathrm{C}^{17} \mathrm{O}$ were detected as indicated: $\mathrm{R}(2), \mathrm{R}(1), \mathrm{R}(0)$, $\mathrm{Q}(1), \mathrm{Q}(2)$. The line positions of the ${ }^{12} \mathrm{C}^{16} \mathrm{O}$ and ${ }^{13} \mathrm{C}^{16} \mathrm{O}$ lines in this wavelength region are also indicated. Overlapping of the ${ }^{12} \mathrm{C}^{16} \mathrm{O}$ and ${ }^{12} \mathrm{C}^{17} \mathrm{O}$ lines does not occur for the five lines of ${ }^{12} \mathrm{C}^{17} \mathrm{O}$ identified here. The peak on the left flank of the $\mathrm{R}(2)$ line 
of ${ }^{13} \mathrm{C}^{16} \mathrm{O}$ (indicated by an asterisk) is at the expected position for all of the following: ${ }^{12} \mathrm{C}^{16} \mathrm{O} \mathrm{R}(13),{ }^{12} \mathrm{C}^{17} \mathrm{O} \mathrm{Q}(3)$ and the ${ }^{\mathrm{S}} \mathrm{R}(1)$ line of the $\mathrm{d}^{3} \Delta\left(\mathrm{v}^{\prime}=5\right)-\mathrm{X}^{1} \Sigma^{+}\left(\mathrm{v}^{\prime \prime}=0\right)$ singlettriplet band. This measured line could be due to the contributions of all of these, but an assignment is not made.

\subsection{The effect of experimental conditions}

The detection of the weak rovibronic lines of the rarer isotopomers $\left({ }^{13} \mathrm{C}^{16} \mathrm{O},{ }^{12} \mathrm{C}^{18} \mathrm{O}\right.$ and $\left.{ }^{12} \mathrm{C}^{17} \mathrm{O}\right)$ is facilitated by the inherent sensitivity of the experimental method, combined with a number of conditions that have been optimised in this experiment. These conditions are: (1) a suitable choice of $\mathrm{CO}$ fraction in the supersonic expansion, (2) the temporal overlap of gas and laser pulses and (3) the gas pulse duration. By adjusting these conditions either the signal strengths of the rare isotopomer transitions or the signal strengths of the ${ }^{12} \mathrm{C}^{16} \mathrm{O}$ transitions can be selectively enhanced. The detection of the weak rovibronic lines of the ${ }^{12} \mathrm{C}^{16} \mathrm{O}$ forbidden transitions is also facilitated by these conditions and improved further by selecting a suitable signal integration time. These experimental conditions are discussed below.

\subsubsection{Choice of $\mathrm{CO}$ fraction in supersonic expansion}

In a supersonic expansion, the terminal temperature depends on the ratio of specific heat capacities $\mathrm{C}_{\mathrm{p}} / \mathrm{C}_{\mathrm{v}}$ of the gas mixture. A gas mixture containing a large fraction of atomic carrier gas (typically argon or neon at about $99.95 \%$ of the mixture) therefore results in the lowest sample temperature, producing a spectrum with stronger signals for the $\mathrm{J}=0$ and $\mathrm{J}=1$ lines of the rare isotopomers and less interference of the neighbouring higher $\mathrm{J}$ lines of ${ }^{12} \mathrm{C}^{16} \mathrm{O}$.

However, there is a compromise between low temperature and signal strength, since the total sample density depends linearly on the $\mathrm{CO}$ fraction in the mixture and the 
average signal strength is expected to depend linearly on sample density. Therefore the lowest temperatures obtained are associated with weak average signal strengths. The effect of the CO fraction was investigated systematically. The results for the $\mathrm{A}^{1} \Pi-\mathrm{X}^{1} \Sigma^{+}\left(\mathrm{v}^{\prime}=2, \mathrm{v}^{\prime \prime}=0\right)$ band are illustrated in Figures 4 and 5. Figure 4 illustrates that an increase in sample density (by using a larger $\mathrm{CO}$ fraction in the gas mixture) significantly increased the signal-to-noise ratio of most lines as expected. However, it is clear that the signal strengths of the ${ }^{13} \mathrm{C}^{16} \mathrm{O}$ lines show a larger relative increase with the $\mathrm{CO}$ fraction than the signal strengths of the corresponding ${ }^{12} \mathrm{C}^{16} \mathrm{O}$ lines.

In general the increases in signal strengths of individual lines were found to scale nonlinearly with the $\mathrm{CO}$ fraction, and to depend in a nonlinear way on the relative signal strength. As illustrated in more detail in Figure 5, the same increase in CO fraction results in a much larger relative increase in the signal strengths of weak lines, irrespective of their J value, than of strong lines. For example, the relatively weak signal of the $\mathrm{R}(0)$ line of ${ }^{12} \mathrm{C}^{17} \mathrm{O}$ increases with $300 \%$ while the strong signal of the $\mathrm{Q}(1)$ line of ${ }^{12} \mathrm{C}^{16} \mathrm{O}$ increases with $34 \%$ when the $\mathrm{CO}$ fraction is increased from $0.6 \%$ to $24 \%$.

The larger relative increase in strength of the signals of weak lines with increased CO fraction is explained in the case of the higher-J lines by the increase in temperature. The larger relative increase of the low-J lines of the rare isotopomers compared to that of ${ }^{12} \mathrm{C}^{16} \mathrm{O}$ can only be explained by self-absorption and saturation effects in the case of the ${ }^{12} \mathrm{C}^{16} \mathrm{O}$ lines. This effect was exploited in our experiment to selectively enhance the weak signals of interest. The higher sample temperature resulting from the larger $\mathrm{CO}$ fraction was found particularly useful in the present study to detect higher-J lines of ${ }^{12} \mathrm{C}^{17} \mathrm{O}$ than would have been observed at typical conditions with colder samples. 


\subsubsection{Temporal overlap of pulses}

The temporal overlap of the gas and laser pulses is determined by the delay time between the gas pulse trigger and the laser trigger. By measuring delay scans for spectral lines of the different isotopomers, it was found that the peak fluorescence signal occurs at a different delay time for the rarer isotopomers than for ${ }^{12} \mathrm{C}^{16} \mathrm{O}$, as illustrated in Figure 6.

The flattened shape of the ${ }^{12} \mathrm{C}^{16} \mathrm{O}$ delay scan is not due to signal saturation at the photomultiplier tube, since weaker ${ }^{12} \mathrm{C}^{16} \mathrm{O}$ lines also exhibit this shape. One possible explanation is the process of self-absorption, whereby the LIF signal is reduced by reabsorption of the fluorescence in the gas pulse. This information on the temporal overlap facilitates selection of the optimal delay time for a spectral measurement of the rare $\mathrm{CO}$ isotopomers $(0.6 \mathrm{~ms})$, or of the ${ }^{12} \mathrm{C}^{16} \mathrm{O}$ isotopomer $(0.42 \mathrm{~ms})$.

\subsubsection{Gas pulse duration}

The effect of gas pulse duration on the LIF signal strength was investigated using delay scans. Shorter gas pulse durations are typically preferable, due to the lower background pressure in the vacuum chamber and therefore lower temperatures in the subsequent gas pulses. However, an increase in the gas pulse length was shown to increase the peak signals of the ${ }^{12} \mathrm{C}^{17} \mathrm{O}$ isotopomer lines during the delay scan. No such increase was observed for ${ }^{12} \mathrm{C}^{16} \mathrm{O}$. The LIF signal strengths of the rare isotopomer transitions were observed to be optimal at pulse durations of $0.65 \mathrm{~ms}$ or longer as shown in Figure 7. We consider the signal variation shown by the ${ }^{12} \mathrm{C}^{17} \mathrm{O}$ isotopomer to represent the true temporal density variation of the gas jet, whereas the signal variation of the ${ }^{12} \mathrm{C}^{16} \mathrm{O}$ isotopomer is probably strongly influenced by selfabsorption, as discussed in the previous section. 


\subsubsection{Detection gate setting}

A number of forbidden transitions of ${ }^{12} \mathrm{C}^{16} \mathrm{O}$ were observed in the wavelength regions covered in this study and are published here for the first time. These refer to rovibronic excitations from the singlet ground state to triplet excited states. The temporal variation of the fluorescence signals resulting from excitation to singlet and triplet excited states respectively are shown in Figure 8 as measured by a $500 \mathrm{MHz}$ oscilloscope. A weak singlet line and a relatively strong triplet line (probably due to significant singlet character) were chosen to have comparable peak signals.

By setting the boxcar to integrate over a narrow detection gate overlapping in time with the singlet-singlet fluorescence peak, these transitions are recorded with highest selectivity. By selecting a delayed detection gate with a longer duration, starting after the singlet-singlet fluorescence has dropped to practically zero, the longer phosphorescence lifetime of the triplet state can be used to selectively detect singlettriplet transitions. The spectra in Figure 9 were recorded over the same wavelength range using the two different settings as described above. These spectra illustrate the ability to selectively measure these singlet-triplet transitions even if they overlap with singlet-singlet transitions and produce weaker signals due to a smaller transition probability for excitation.

\subsection{Forbidden transitions of ${ }^{12} \mathrm{C}^{16} \mathrm{O}$}

In this study, 32 lines of ${ }^{12} \mathrm{C}^{16} \mathrm{O}$ corresponding to excitation from the singlet electronic ground state $\mathrm{X}^{1} \Sigma^{+}$to triplet electronic excited states were detected. According to a comprehensive review by Eidelsberg and Rostas [10] and the online database [11] maintained by Eidelsberg, accurate experimental wavelengths for 10 of these lines have not been experimentally determined before. The singlet-singlet lines in the vicinity of each singlet-triplet band were used for wavelength calibration. The 
calibrated wavelengths of the measured singlet-triplet lines were compared to their values from literature (for the 22 lines that have been published $[10,11]$ ) and the average difference is slightly larger than the uncertainty of the singlet-singlet band calibrations, indicating a slightly larger uncertainty on these wavelengths. The uncertainties of the wavelengths in each band are given below in each subsection below.

These lines are observed to have similar experimental spectral linewidths as the singlet-singlet lines. This may be explained by the experimental limitation induced by the laser bandwidth, which is larger than the linewidths of both the singlet-singlet and singlet-triplet transitions.

\subsection{1 $\mathrm{e}^{3} \Sigma^{-}\left(\mathrm{v}^{\prime}=1\right)-\mathrm{X}^{1} \Sigma^{+}\left(\mathrm{v}^{\prime \prime}=0\right)$}

This band was recorded to the short wavelength side of the $\mathrm{A}^{1} \Pi-\mathrm{X}^{1} \Sigma^{+}\left(\mathrm{v}^{\prime}=0, \mathrm{v}^{\prime \prime}=0\right)$ band and is shown in detail in Figure 10. This figure shows all 10 identified lines with the labelling scheme adopted from Morton and Noreau [4]. All 10 identified lines of this band could be compared to their literature wavelengths [10] and are included in Table 1 . The uncertainty of the experimental wavelengths taken as the standard deviation of the differences between the experimental and literature wavelengths is $0.3 \mathrm{pm}$, calculated using wavelength data with one more digit than shown in Table 1.

\subsection{2 $\mathrm{d}^{3} \Delta\left(\mathrm{v}^{\prime}=5\right)-\mathrm{X}^{1} \Sigma^{+}\left(\mathrm{v}^{\prime},=0\right)$}

This band was recorded among the ${ }^{13} \mathrm{C}^{16} \mathrm{O}$ lines of the $\mathrm{A}^{1} \Pi-\mathrm{X}^{1} \Sigma^{+}\left(\mathrm{v}^{\prime}=1, \mathrm{v}^{\prime \prime}=0\right)$ band and is shown in detail in Figure 11. This figure shows all 12 identified lines, of which nine are new results, with the labelling scheme adopted from Morton and Noreau [4]. The experimentally measured wavelengths and the literature wavelengths of the three 
lines that are documented elsewhere [10] are given in Table 2. The wavelength uncertainty calculated from this data is $0.7 \mathrm{pm}$.

\subsection{3 $\mathrm{a}^{3} \Sigma^{+}\left(\mathrm{v}^{\prime}=14\right)-\mathrm{X}^{1} \Sigma^{+}\left(\mathrm{v}^{\prime},=0\right)$}

This band was recorded among the ${ }^{12} \mathrm{C}^{16} \mathrm{O}$ lines of the $\mathrm{A}^{1} \Pi-\mathrm{X}^{1} \Sigma^{+}\left(\mathrm{v}^{\prime}=4, \mathrm{v}{ }^{\prime \prime}=0\right)$ band and is shown in detail in Figure 12. Table 3 gives the experimental wavelengths of the 10 lines identified in the spectrum with the labelling scheme adopted from Morton and Noreau [4], together with literature wavelengths $[10,11]$. The ${ }^{\mathrm{P}} \mathrm{P}(2)$ line has not been experimentally measured before and two others, ${ }^{\mathrm{P}} \mathrm{Q}(1)$ and ${ }^{\mathrm{P}} \mathrm{Q}(2)$, have only recently been added to the online database [11]. The experimental uncertainty in this case is $0.4 \mathrm{pm}$.

\subsection{Band origins of ${ }^{12} \mathrm{C}^{17} \mathrm{O}$}

The band origins (the positions of the forbidden $\mathrm{Q}(0)$ lines) were determined for all four isotopomers in all six vibronic bands of the Fourth Positive System that were studied (i.e. excluding singlet-triplet bands). The band origins were calculated by two methods that yielded the same results within the uncertainty of the data. The theoretical position of the band origin relative to the neighbouring $\mathrm{R}(0)$ and $\mathrm{Q}(1)$ lines was calculated, and the resulting ratio was used to interpolate the position of the band origin from experimental wavelengths of the $\mathrm{R}(0)$ and $\mathrm{Q}(1)$ lines. Secondly, linear least squares fits of the wavenumbers of the $Q(J)$ lines were used according to the expression $Q(J)=v_{0}+\left(B{ }_{v}-B{ }^{\prime}{ }_{v}\right) J(J+1)[12]$. From the band origin data the vibrational isotopic shifts of the rare isotopomers relative to ${ }^{12} \mathrm{C}^{16} \mathrm{O}$ were calculated. The resulting band origins and isotopic shifts of ${ }^{12} \mathrm{C}^{17} \mathrm{O}$, which constitute new data, are presented in Table 4. The asterisk indicates a variation in the determination of the band origin, since the $\mathrm{Q}$ lines could not be measured for the $\mathrm{A}^{1} \Pi-\mathrm{X}^{1} \Sigma^{+}\left(\mathrm{v}^{\prime}=0, \mathrm{v}^{\prime}{ }^{\prime}=0\right)$ band due to spectral congestion. The band origin was therefore calculated from the 
wavelength of the $\mathrm{R}(0)$ line alone in this case. The experimental isotopic shifts of the ${ }^{12} \mathrm{C}^{17} \mathrm{O}$ bands are compared to theoretical estimates of the isotopic shifts calculated by using the mass-independent Dunham parameters of George et al. [13] for the $\mathrm{X}^{1} \Sigma^{+}$ state and the molecular constants of Huber and Herzberg [14] for the $A^{1} \Pi$ states. The band origin values calculated for the $\mathrm{X}^{1} \Sigma^{+}\left(\mathrm{v}^{\prime \prime}=0\right)$ state of ${ }^{12} \mathrm{C}^{17} \mathrm{O}$ and ${ }^{12} \mathrm{C}^{16} \mathrm{O}$ are claimed to have an uncertainty of about $7 \times 10^{-7} \mathrm{~cm}^{-1}(20 \mathrm{kHz})[13]$ and the experimental values have an uncertainty of about $0.09 \mathrm{~cm}^{-1}$ (paragraph 3.1). Therefore the relatively large differences between the measured and literature values are considered a measure of the uncertainty in the band origin values calculated from the molecular constants for the $\mathrm{A}^{1} \Pi$ state. The uncertainties in these values may be due to breakdown of the Born-Openheimer approximation [15].

\section{Conclusions}

In this study, the experimental conditions were optimised for measurement of rovibronic transitions of rare $\mathrm{CO}$ isotopomers and forbidden singlet-triplet transitions in a natural CO sample. The resulting high sensitivity allowed the detection of a number of lines in $6{ }^{12} \mathrm{C}^{17} \mathrm{O}$ rovibronic bands for which band origins and vibrational isotopic shifts have been reported here for the first time. These isotopic shifts cannot be reproduced within the experimental uncertainty from data previously available in literature. A number of lines resulting from forbidden singlet-triplet transitions of ${ }^{12} \mathrm{C}^{16} \mathrm{O}$ have been detected and the experimental wavelengths of 10 lines are presented here for the first time. The considerations and results on the influence of the experimental parameters reported here may be applied in similar experiments. The low detection limit reached in this work by optimised experimental conditions facilitates future work focusing on the further recording of forbidden transitions which are important in astrophysics. 


\section{Acknowledgements}

The project is supported by the CSIR National Laser Centre, South Africa. Anton du Plessis acknowledges the support of the South African Department of Labour for his

Ph.D. bursary for 2003-2005. Anton du Plessis also acknowledges the CSIR Young

Researcher Establishment Fund for supporting his attendance of the $19^{\text {th }}$ International

Conference on High Resolution Molecular Spectroscopy in Prague, 29 August - 2

September 2006. 


\section{References}

[1] E.F. Van Dishoeck, J.H. Black, Astrophys. J. 334 (1988) 771.

[2] D.S. Balser, J.P. McMullin, T.L. Wilson, Astrophys. J. 572 (2002) 326.

[3] Y. Sheffer, D.L. Lambert, S.R. Federman, Astrophys. J. 574 (2002) L171.

[4] D.C. Morton, L. Noreau, Astrophys. J. Suppl. S. 95 (1994) 301.

[5] L.M. Beaty, V.D. Braun, K.P. Huber, A.C. Le Floch, Astrophys. J. Suppl. S. 109 (1997) 269.

[6] A. Du Plessis, E.G. Rohwer, C.M. Steenkamp, Astrophys. J. Suppl. S. 165 (2006) 432.

[7] A. Du Plessis, C.M. Steinmann, E.G. Rohwer, S. Afr. J. Sci. 101 (2005) 93-95.

[8] C.M. Steenkamp, A. Du Plessis, E.G. Rohwer, S. Afr. J. Sci. 101 (2005) 272-275.

[9] C.M. Steinmann, E.G. Rohwer, H. Stafast, Astrophys. J. 590 (2003) L123.

[10] M. Eidelsberg, F. Rostas, Astrophys. J. Suppl. S. 145 (2003) 89.

[11] Http://amrel.obspm.fr/molat/index.php?page=pages/Molecules/CO-

$\underline{\text { Michele/CO.php }}$

[12] C.V.V. Prasad, G.L. Bhale, S. Paddi Reddy, J. Mol. Spectrosc. 104 (1984) $165-$ 173.

[13] T. George, W. Urban, A. Le Floch, J. Mol. Spectrosc. 165 (1994) 500-505.

[14] K.P. Huber, G. Herzberg, Molecular Spectra and Molecular Structure. IV. Constants of Diatomic Molecules, Van Nostrand-Reinhold, New York, 1979. [15] A. Le Floch, Mol. Phys. 72 (1991) 133-144. 


\section{Figures}

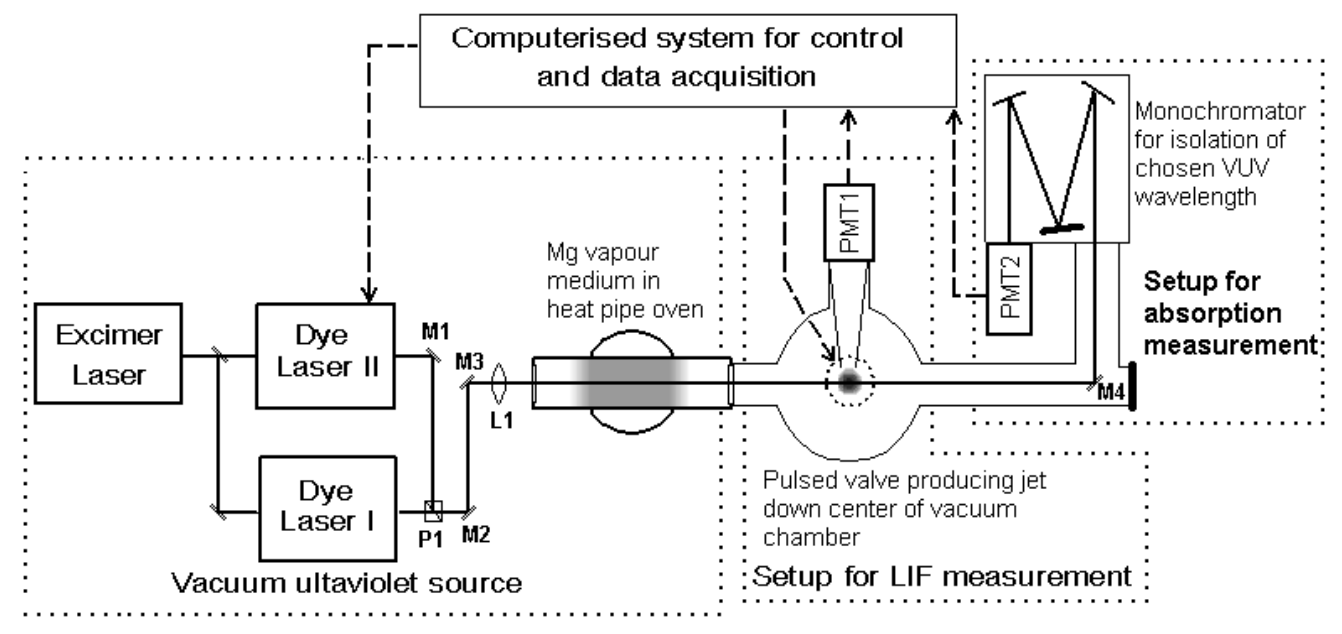

Figure 1: Schematic of the experimental setup in three sections: the vacuum

ultraviolet laser source; the setup for LIF measurement in a pulsed supersonic expansion; and the setup for absorption measurement.

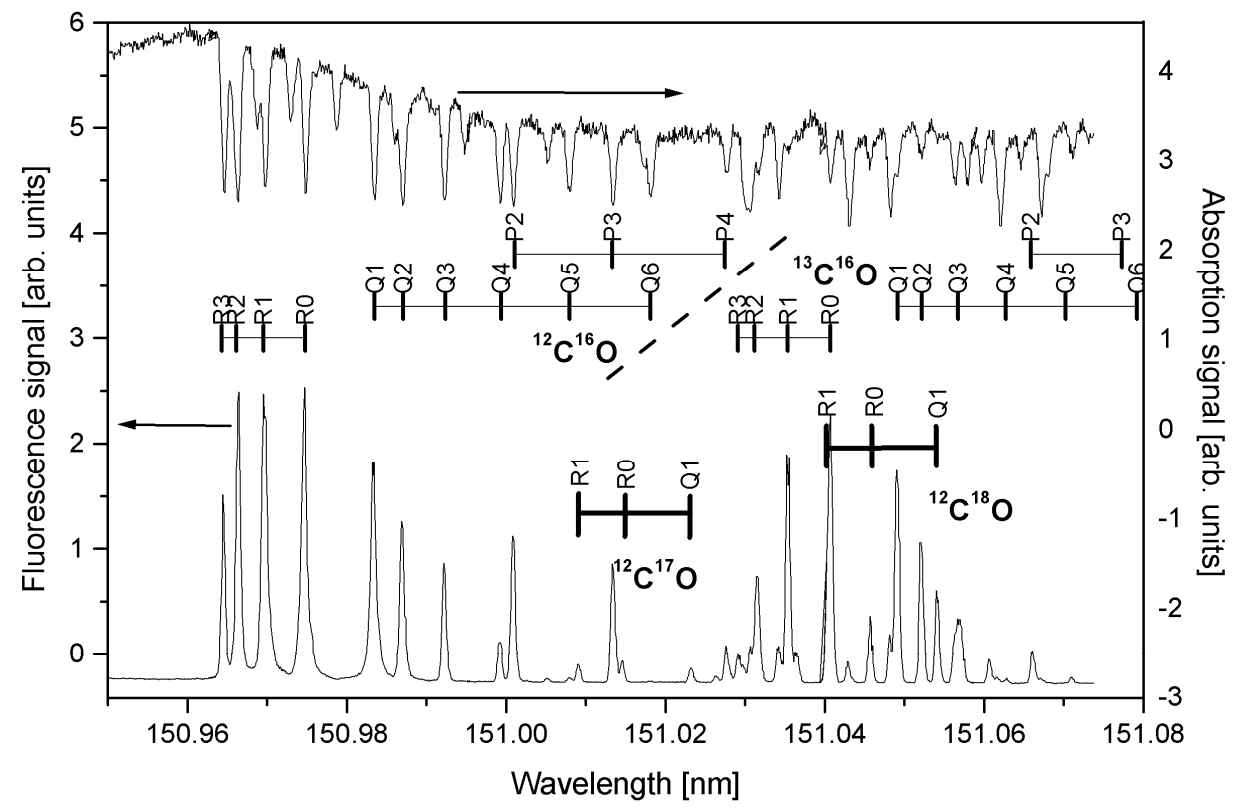


Figure 2: Experimental LIF (lower) and absorption (upper) spectra of the $\mathrm{A}^{1} \Pi$ $\mathrm{X}^{1} \Sigma^{+}\left(\mathrm{v}^{\prime}=1, \mathrm{v}^{\prime \prime}=0\right)$ band, with the positions of the lowest-J lines of ${ }^{12} \mathrm{C}^{16} \mathrm{O}$ and ${ }^{13} \mathrm{C}^{16} \mathrm{O}$ indicated, as well as $\mathrm{R}(0), \mathrm{R}(1)$ and $\mathrm{Q}(1)$ of ${ }^{12} \mathrm{C}^{17} \mathrm{O}$ and ${ }^{12} \mathrm{C}^{18} \mathrm{O}$.

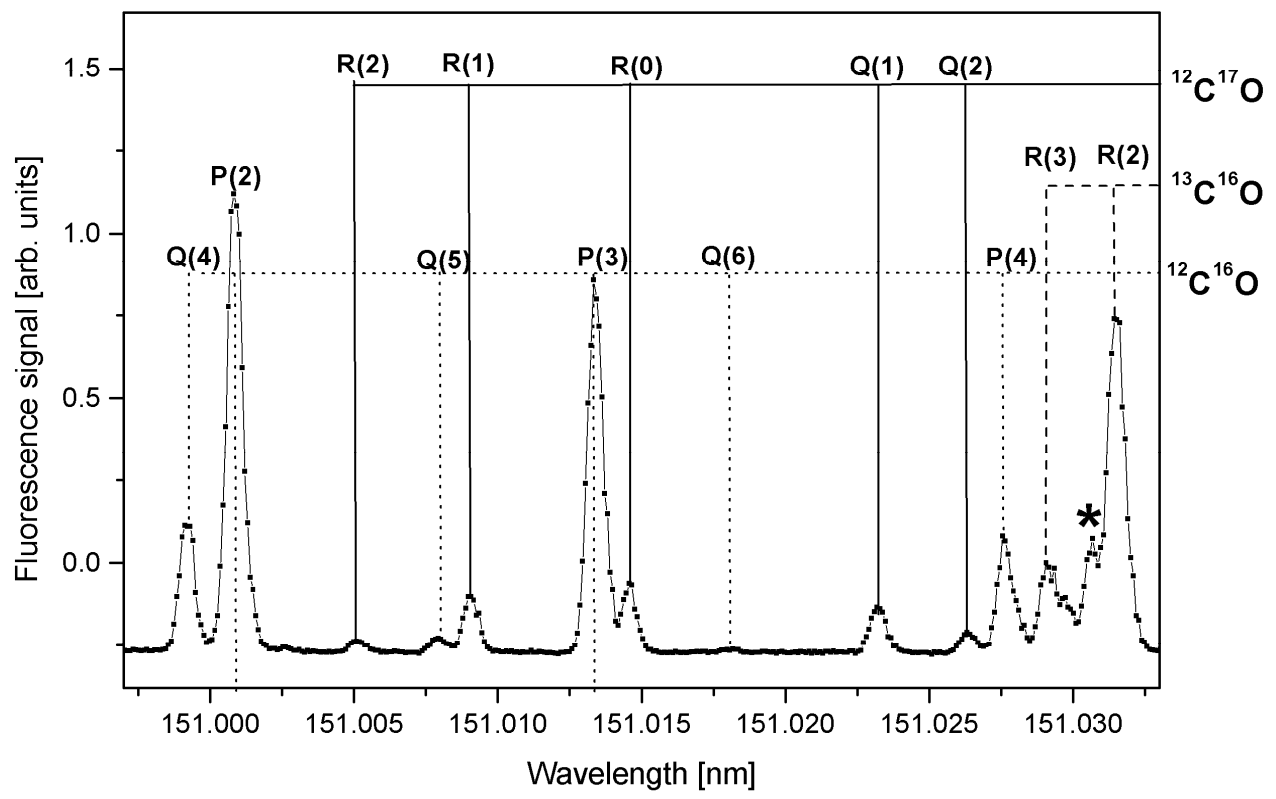

Figure 3: Experimental LIF spectrum of the $\mathrm{A}^{1} \Pi-\mathrm{X}^{1} \Sigma^{+}\left(\mathrm{v}^{\prime}=1, \mathrm{v}^{\prime \prime}=0\right)$ band, indicating the positions of ${ }^{12} \mathrm{C}^{17} \mathrm{O}$ lines (solid lines), the positions of ${ }^{12} \mathrm{C}^{16} \mathrm{O}$ lines (dotted lines) and of some ${ }^{13} \mathrm{C}^{16} \mathrm{O}$ lines (dashed lines). The line indicated with an asterisk comprises overlapping lines of various species. 


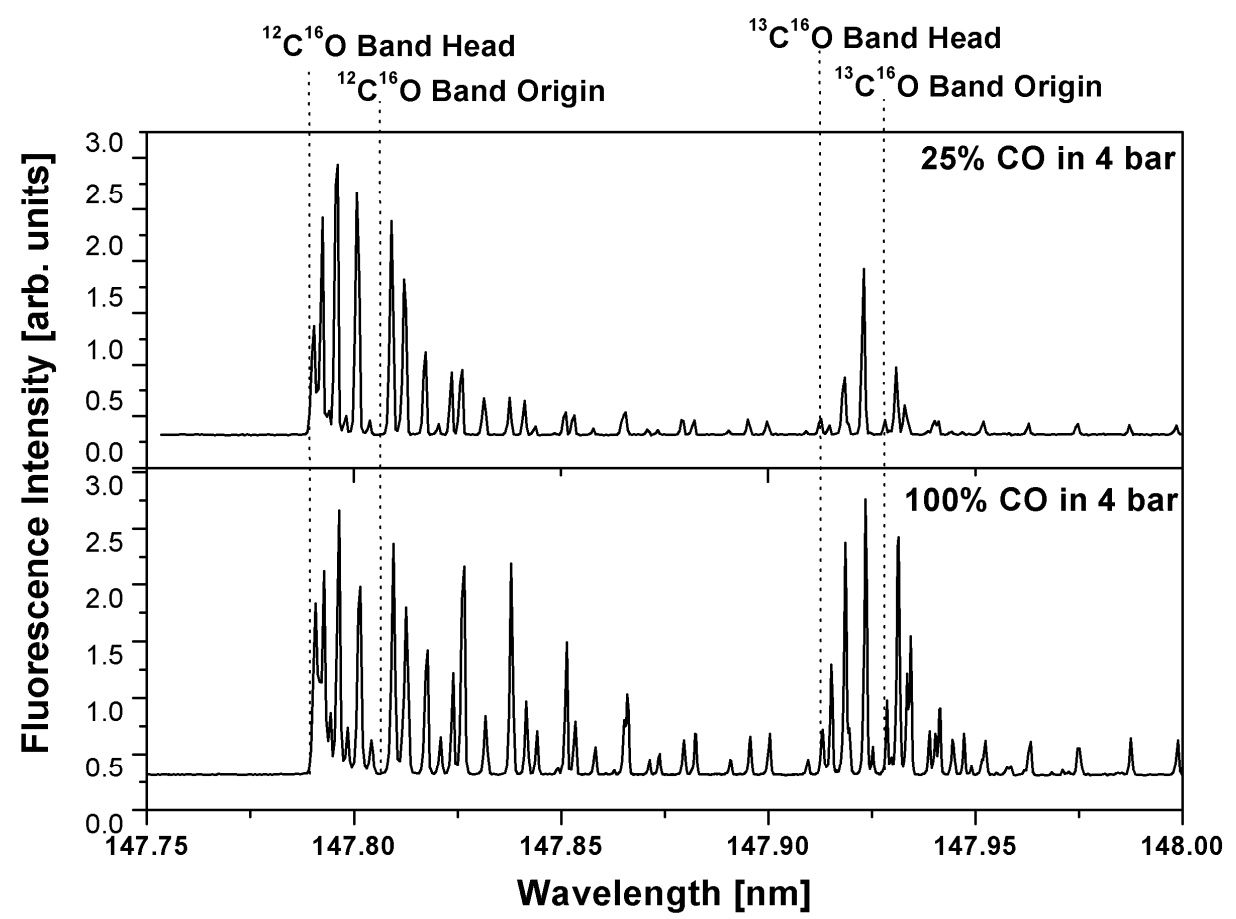

Figure 4: The effect of an increase in $\mathrm{CO}$ density, illustrated by $\mathrm{A}^{1} \Pi-$ $\mathrm{X}^{1} \Sigma^{+}\left(\mathrm{v}^{\prime}=2, \mathrm{v}^{\prime \prime}=0\right)$ band spectra, recorded using $25 \% \mathrm{CO}$ (top) and $100 \% \mathrm{CO}$ (bottom) in 4 bar stagnation pressure with Ar as carrier gas. 


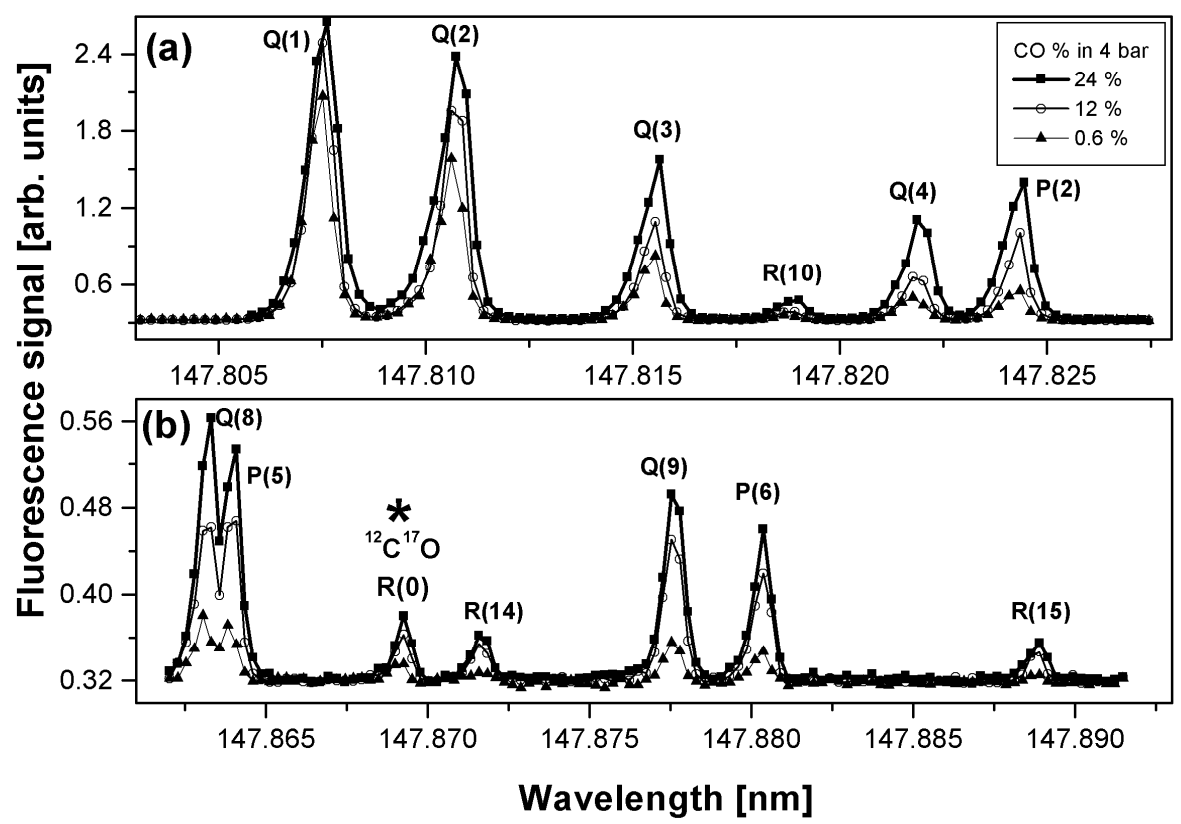

Figure 5 (a) and (b): The effect of an increase in $\mathrm{CO}$ density, illustrated by two regions in the $\mathrm{A}^{1} \Pi-\mathrm{X}^{1} \Sigma^{+}\left(\mathrm{v}^{\prime}=2, \mathrm{v}\right.$ ' $\left.=0\right)$ band spectra, recorded using $0.6 \%, 12 \%$ and $24 \% \mathrm{CO}$ in 4 bar stagnation pressure with Ar carrier gas. The strong signals of the lowest-J lines of ${ }^{12} \mathrm{C}^{16} \mathrm{O}$ are shown in (a) and the much weaker signals of the higher-J lines of ${ }^{12} \mathrm{C}^{16} \mathrm{O}$ surrounding the ${ }^{12} \mathrm{C}^{17} \mathrm{O} \mathrm{R}(0)$ line (indicated with an asterisk) in (b). 


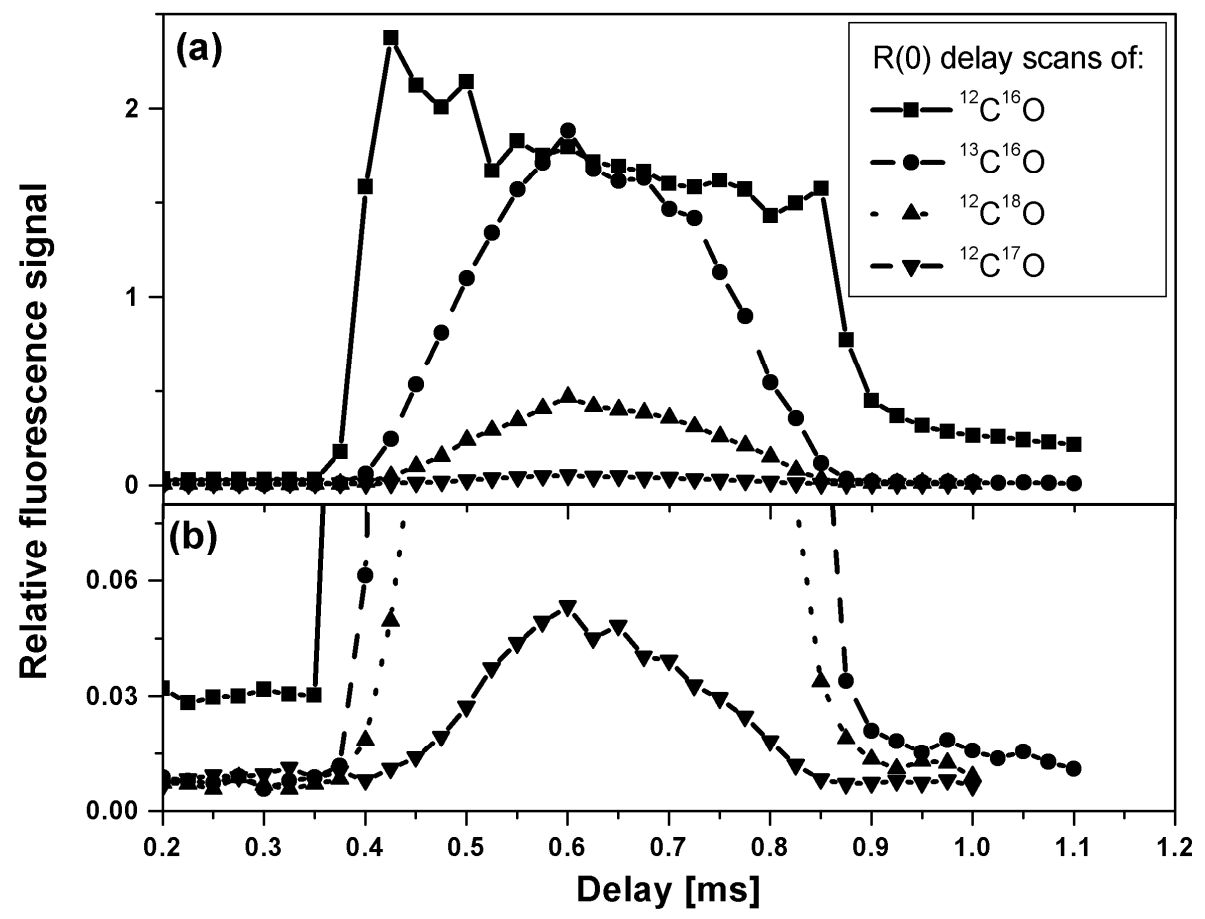

Figure 6: Delay scans of the $R(0)$ lines of all four isotopomers in their $A^{1} \Pi-$

$\mathrm{X}^{1} \Sigma^{+}\left(\mathrm{v}^{\prime}=2, \mathrm{v}^{\prime},=0\right)$ bands, scaled to the ${ }^{12} \mathrm{C}^{16} \mathrm{O}$ signal in (a) and to the ${ }^{12} \mathrm{C}^{17} \mathrm{O}$ signal level in (b). 


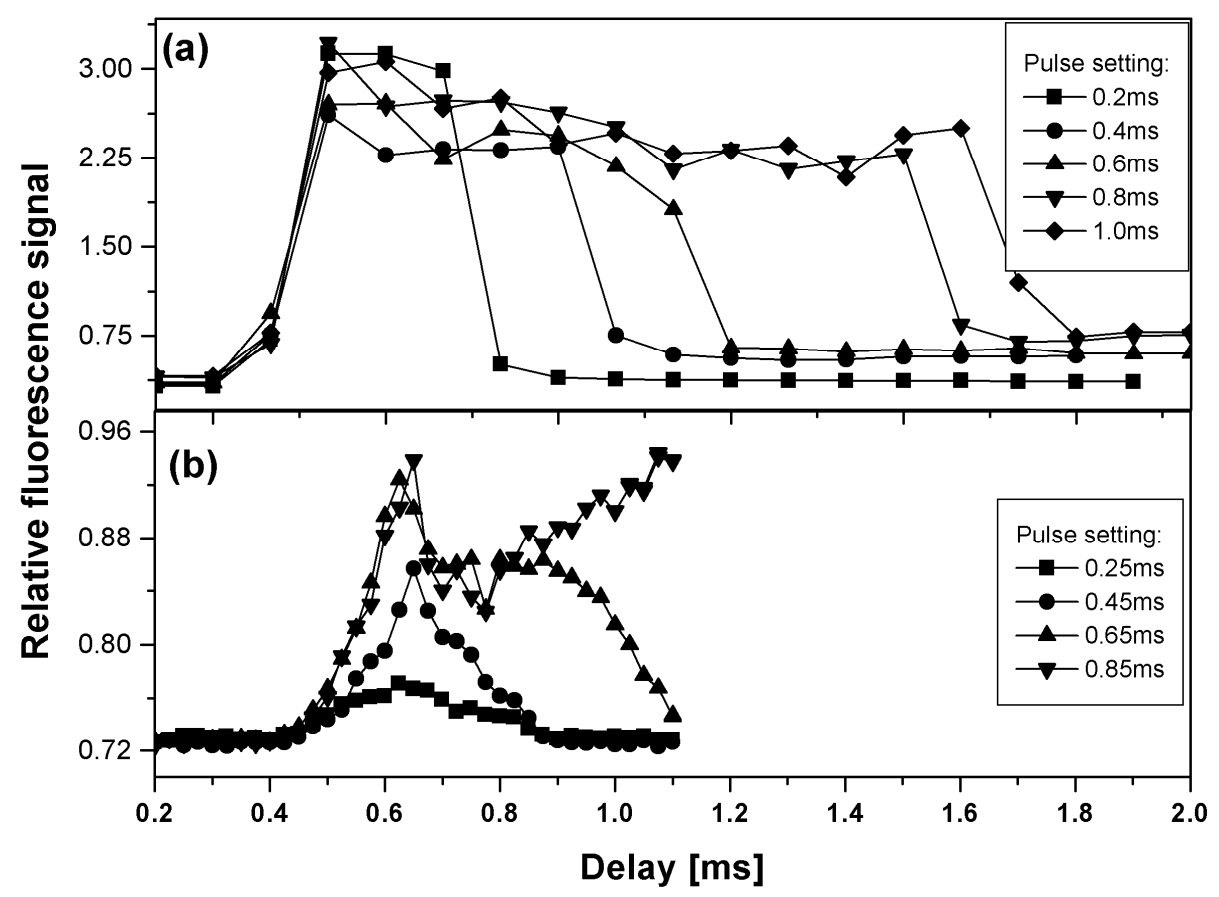

Figure 7: Delay scans at different pulse durations for (a) the $\mathrm{R}(0)$ line of ${ }^{12} \mathrm{C}^{16} \mathrm{O}$, and (b) the $\mathrm{R}(0)$ line of ${ }^{12} \mathrm{C}^{17} \mathrm{O}$. The shortest pulse duration obtained with the pulse driver was approximately $0.25 \mathrm{~ms}$. 


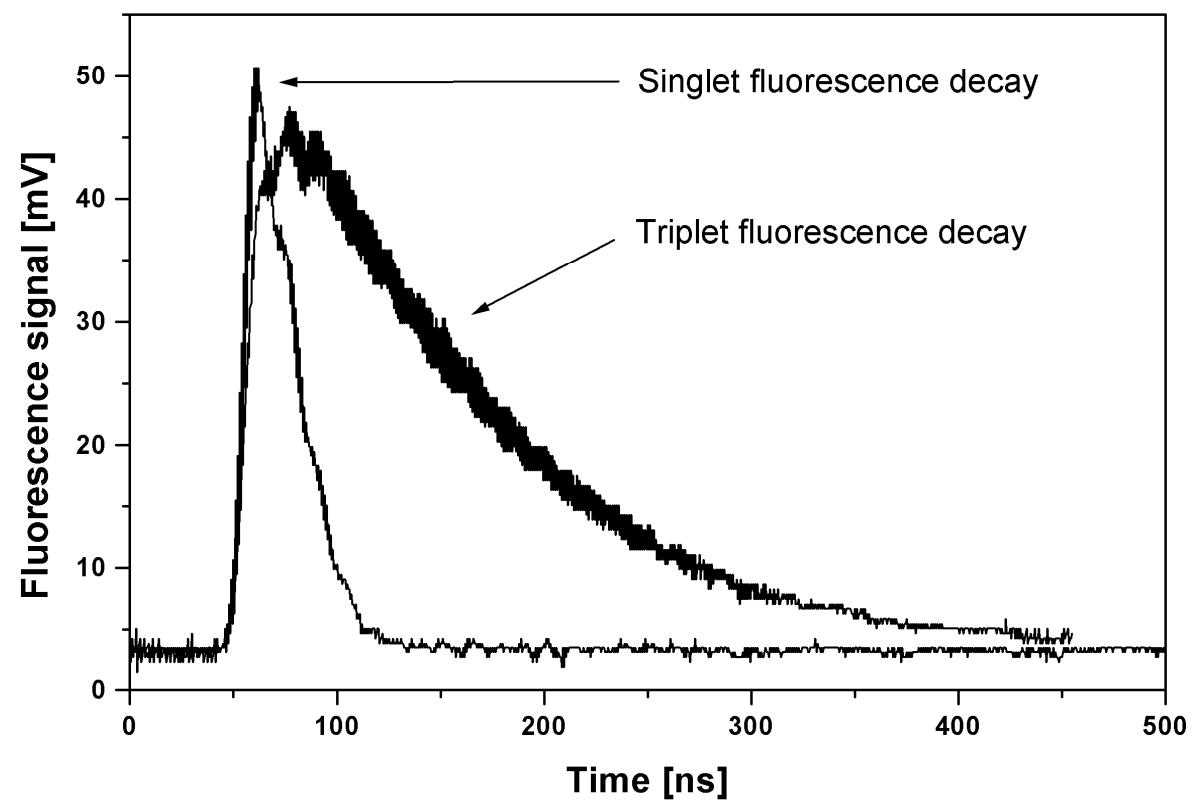

Figure 8: Oscilloscope traces showing the decay of the fluorescence from a singlet and a triplet excited state of ${ }^{12} \mathrm{C}^{16} \mathrm{O}$ respectively. 


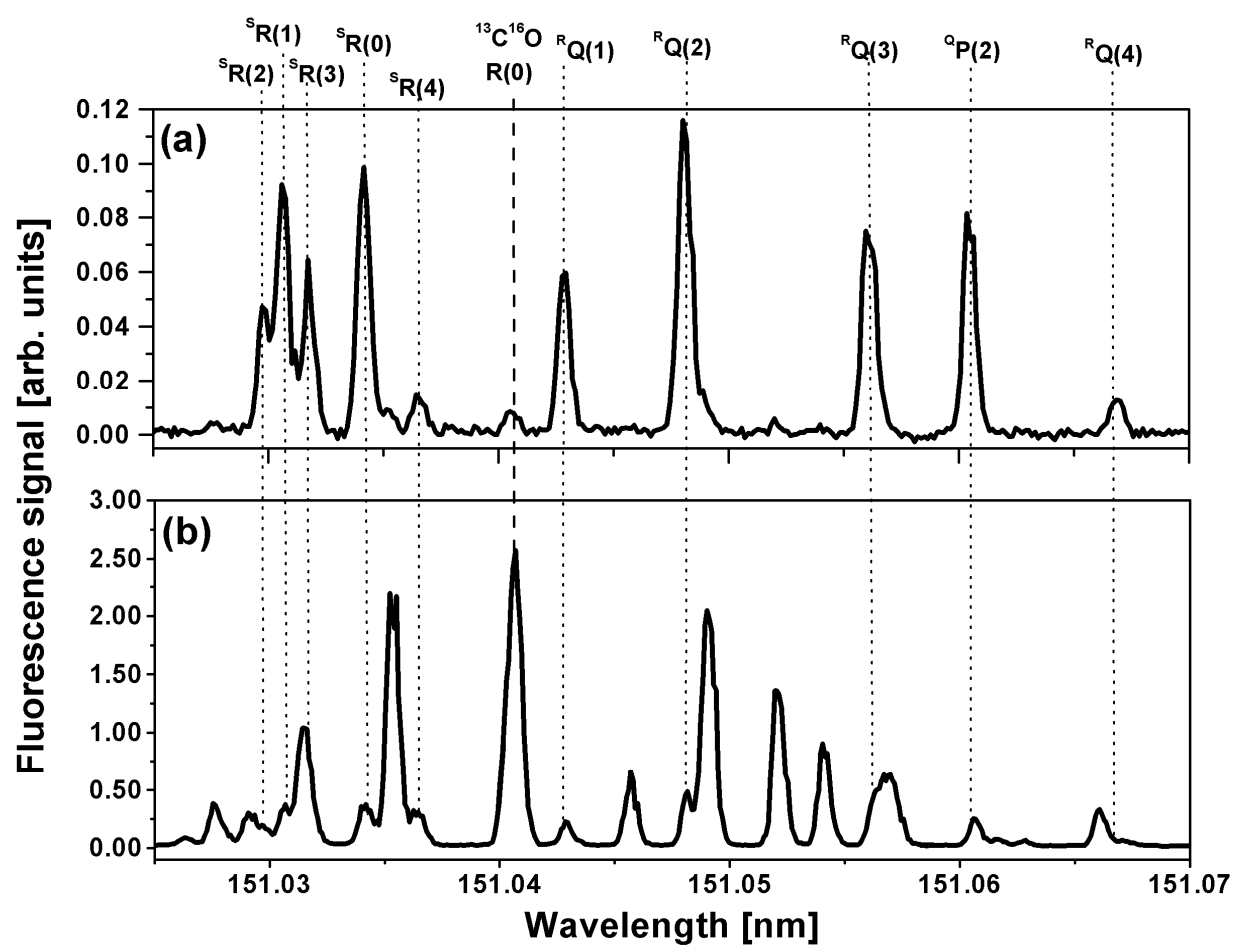

Figure 9: Two spectra of the same wavelength range, containing both singlet-singlet as well as singlet-triplet transitions, measured while using the gate setting optimised for singlet-singlet transitions (b), and using a delayed gate setting optimised for detection of singlet-triplet transitions (a). These singlet-triplet transitions are in the $\mathrm{d}^{3} \Delta\left(\mathrm{v}^{\prime}=5\right)-\mathrm{X}^{1} \Sigma^{+}\left(\mathrm{v}^{\prime},=0\right)$ band. 


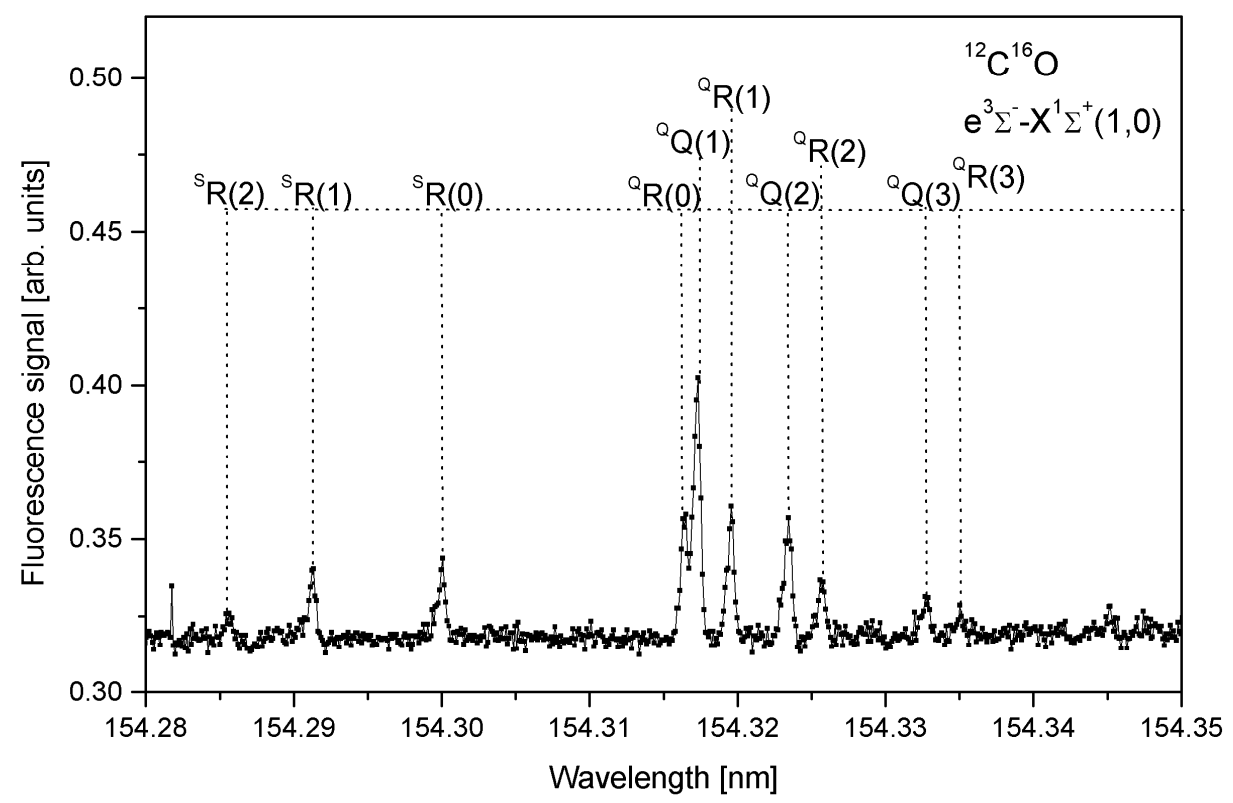

Figure 10: Experimental LIF spectrum of the $\mathrm{e}^{3} \Sigma^{-}\left(\mathrm{v}^{\prime}=1\right)-\mathrm{X}^{1} \Sigma^{+}\left(\mathrm{v}^{\prime \prime}=0\right)$ band, with the positions of all identified lines indicated. 


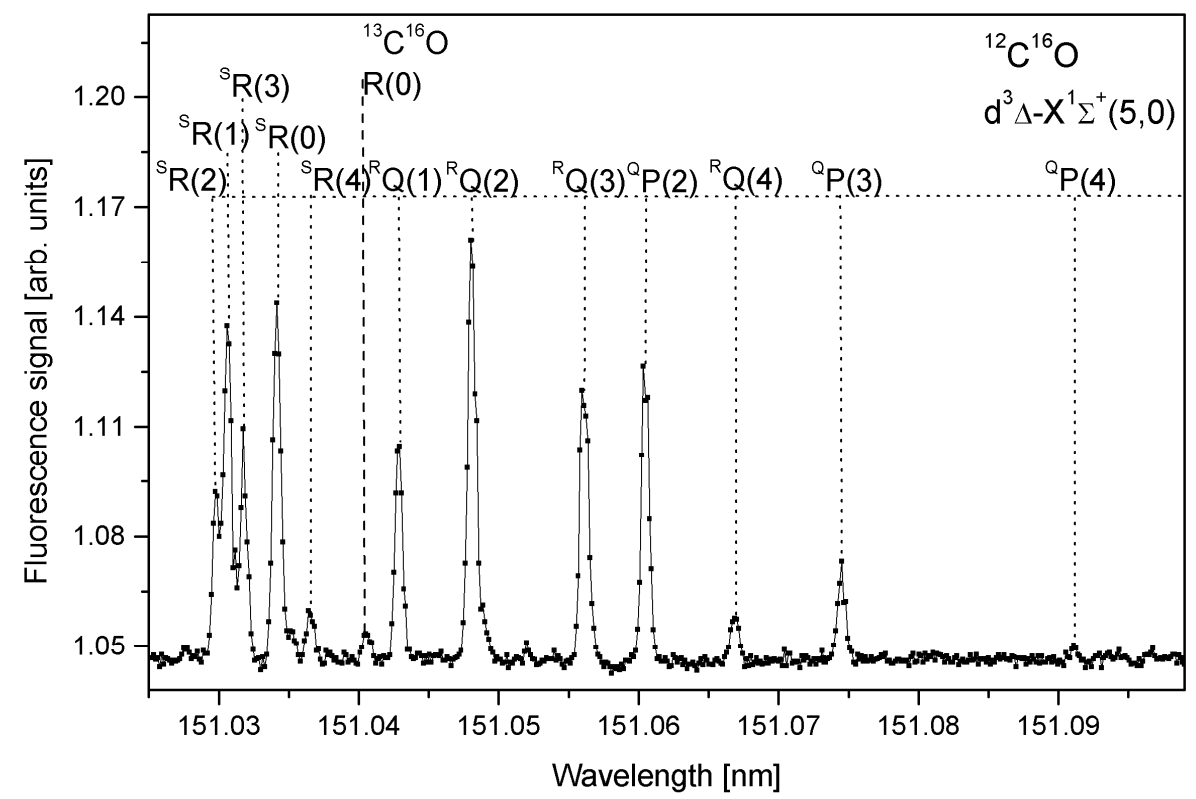

Figure 11: Experimental LIF spectrum of the $\mathrm{d}^{3} \Delta\left(\mathrm{v}^{\prime}=5\right)-\mathrm{X}^{1} \Sigma^{+}\left(\mathrm{v}^{\prime \prime}=0\right)$ band, with the positions of all identified lines indicated. 


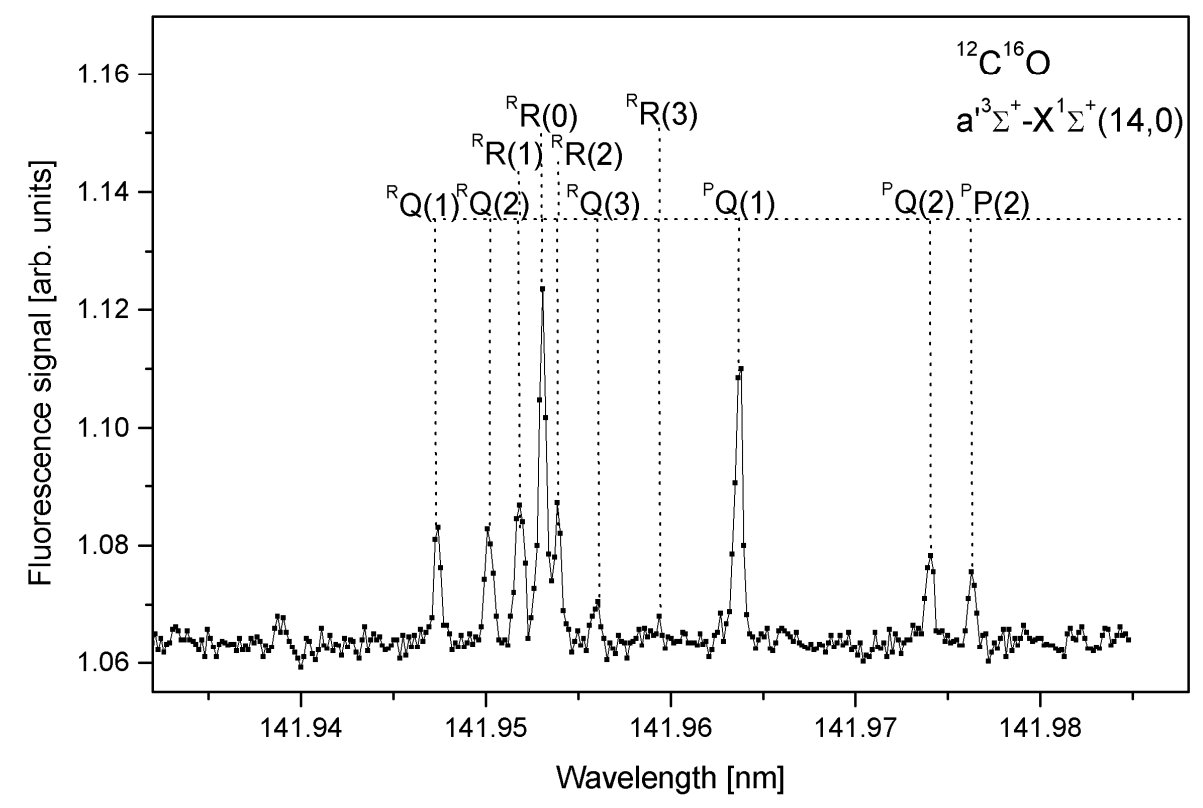

Figure 12: Experimental LIF spectrum of the $\mathrm{a}^{\prime}{ }^{3} \Sigma^{+}\left(\mathrm{v}^{\prime}=14\right)-\mathrm{X}^{1} \Sigma^{+}\left(\mathrm{v}^{\prime \prime}=0\right)$ band, with the positions of all identified lines indicated. 


\section{Tables}

Table 1: Experimentally measured wavelengths for the $\mathrm{e}^{3} \Sigma^{-}\left(\mathrm{v}^{\prime}=1\right)-\mathrm{X}^{1} \Sigma^{+}\left(\mathrm{v}^{\prime \prime}=0\right)$ band of ${ }^{12} \mathrm{C}^{16} \mathrm{O}$. The experimental uncertainty is $0.0003 \mathrm{~nm}$.

\begin{tabular}{|c|c|c|}
\hline $\begin{array}{l}\text { Line } \\
\text { Label }\end{array}$ & Literature Wavelength [nm] & Measured Wavelength [nm] \\
\hline $\mathrm{QR}(0)$ & 154.3167 & 154.3164 \\
\hline${ }^{\mathrm{Q}} \mathrm{R}(1)$ & 154.3201 & 154.3196 \\
\hline $\mathrm{QR}(2)$ & 154.3263 & 154.3257 \\
\hline $\mathrm{QR}(3)$ & 154.3357 & 154.3350 \\
\hline${ }^{\mathrm{S}} \mathrm{R}(0)$ & 154.3000 & 154.3000 \\
\hline${ }^{\mathrm{S}} \mathrm{R}(1)$ & 154.2911 & 154.2913 \\
\hline${ }^{\mathrm{S}} \mathrm{R}(2)$ & 154.2854 & 154.2856 \\
\hline${ }^{\mathrm{Q}} \mathrm{Q}(1)$ & 154.3174 & 154.3173 \\
\hline${ }^{\mathrm{Q}} \mathrm{Q}(2)$ & 154.3239 & 154.3234 \\
\hline${ }^{\mathrm{Q}} \mathrm{Q}(3)$ & 154.3335 & 154.3328 \\
\hline
\end{tabular}


Table 2: Experimentally measured wavelengths for the $\mathrm{d}^{3} \Delta\left(\mathrm{v}^{\prime}=5\right)-\mathrm{X}^{1} \Sigma^{+}\left(\mathrm{v}^{\prime \prime}=0\right)$ band of ${ }^{12} \mathrm{C}^{16} \mathrm{O}$. The experimental uncertainty is $0.0007 \mathrm{~nm}$.

\begin{tabular}{|l|l|l|}
\hline Line & Literature Wavelength [nm] & Measured Wavelength [nm] \\
Label & & \\
\hline${ }^{\mathrm{S}} \mathrm{R}(0)$ & & 151.0341 \\
\hline${ }^{\mathrm{S}} \mathrm{R}(1)$ & & 151.0306 \\
\hline${ }^{\mathrm{S}} \mathrm{R}(2)$ & & 151.0298 \\
\hline${ }^{\mathrm{S}} \mathrm{R}(3)$ & & 151.0318 \\
\hline${ }^{\mathrm{S}} \mathrm{R}(4)$ & 151.0366 & 151.0365 \\
\hline${ }^{\mathrm{R}} \mathrm{Q}(1)$ & & 151.0429 \\
\hline${ }^{\mathrm{R}} \mathrm{Q}(2)$ & & 151.0480 \\
\hline${ }^{\mathrm{R}} \mathrm{Q}(3)$ & & 151.0561 \\
\hline${ }^{\mathrm{R}} \mathrm{Q}(4)$ & 151.0672 & 151.0911 \\
\hline${ }^{\mathrm{Q}} \mathrm{P}(2)$ & & \\
\hline${ }^{\mathrm{Q}} \mathrm{P}(3)$ & & \\
\hline${ }_{\mathrm{Q}} \mathrm{P}(4)$ & 151.0902 & \\
\hline & & \\
\hline
\end{tabular}


Table 3: Experimentally measured wavelengths for the $\mathrm{a}^{3} \Sigma^{+}\left(\mathrm{v}^{\prime}=14\right)-\mathrm{X}^{1} \Sigma^{+}\left(\mathrm{v}^{\prime \prime}=0\right)$ band of ${ }^{12} \mathrm{C}^{16} \mathrm{O}$. The experimental uncertainty is $0.0004 \mathrm{~nm}$.

\begin{tabular}{|l|l|l|}
\hline Line & Literature Wavelength [nm] & Measured Wavelength [nm] \\
\hline${ }^{\mathrm{R}} \mathrm{Q}(1)$ & 141.9488 & 141.9474 \\
\hline${ }^{\mathrm{R}} \mathrm{Q}(2)$ & 141.9506 & 141.9502 \\
\hline${ }^{\mathrm{R}} \mathrm{Q}(3)$ & 141.9564 & 141.9560 \\
\hline${ }^{\mathrm{R}} \mathrm{R}(1)$ & 141.9520 & 141.9518 \\
\hline${ }^{\mathrm{R}} \mathrm{R}(0)$ & 141.9535 & 141.9531 \\
\hline${ }^{\mathrm{R}} \mathrm{R}(2)$ & 141.9541 & 141.9539 \\
\hline${ }^{\mathrm{R}} \mathrm{R}(3)$ & 141.9595 & 141.9595 \\
\hline${ }^{\mathrm{P}} \mathrm{Q}(1)$ & 141.9641 & 141.9637 \\
\hline${ }^{\mathrm{P}} \mathrm{Q}(2)$ & 141.9743 & \\
\hline${ }^{\mathrm{P}} \mathrm{P}(2)$ & & 1.9763 \\
\hline
\end{tabular}


Table 4: Band origins and vibrational isotopic shifts of ${ }^{12} \mathrm{C}^{17} \mathrm{O}$ calculated from experimental data compared to isotopic shifts calculated from literature data $[13,14]$. The asterisk indicates a variation in the determination of the band origin as discussed in paragraph 3.4.

\begin{tabular}{|c|c|c|c|c|}
\hline \multirow[t]{2}{*}{ Band label } & \multirow{2}{*}{$\begin{array}{l}\text { Band origin } \\
{[\mathrm{nm}]}\end{array}$} & \multicolumn{3}{|c|}{ Vibrational isotopic shift $\left[\mathrm{cm}^{-1}\right]$} \\
\hline & & Measured & Literature & $\begin{array}{l}\text { Measured - } \\
\text { Literature }\end{array}$ \\
\hline $\begin{array}{l}\mathrm{A}^{1} \Pi- \\
\mathrm{X}^{1} \Sigma^{+}\left(\mathrm{v}^{\prime}=5, \mathrm{v}^{\prime \prime}=0\right)\end{array}$ & 139.4122 & 79.3 & 82.2 & -2.9 \\
\hline $\begin{array}{l}\mathrm{A}^{1} \Pi- \\
\mathrm{X}^{1} \Sigma^{+}\left(\mathrm{v}^{\prime}=4, \mathrm{v}^{\prime},=0\right)\end{array}$ & 142.0416 & 65.0 & 65.7 & -0.7 \\
\hline $\begin{array}{l}\mathrm{A}^{1} \Pi- \\
\mathrm{X}^{1} \Sigma^{+}\left(\mathrm{v}^{\prime}=3, \mathrm{v}^{\prime \prime}=0\right)\end{array}$ & 144.8438 & 48.7 & 48.9 & -0.2 \\
\hline $\begin{array}{l}\mathrm{A}^{1} \Pi- \\
\mathrm{X}^{1} \Sigma^{+}\left(\mathrm{v}^{\prime}=2, \mathrm{v}^{\prime},=0\right)\end{array}$ & 147.8334 & 32.1 & 31.8 & 0.3 \\
\hline $\begin{array}{l}\mathrm{A}^{1} \Pi- \\
\mathrm{X}^{1} \Sigma^{+}\left(\mathrm{v}^{\prime}=1, \mathrm{v}^{\prime},=0\right)\end{array}$ & 151.0217 & 17.5 & 14.2 & 3.3 \\
\hline $\begin{array}{l}\mathrm{A}^{1} \Pi- \\
\mathrm{X}^{1} \Sigma^{+}\left(\mathrm{v}^{\prime}=0, \mathrm{v}^{\prime},=0\right)\end{array}$ & $154.4438 *$ & -3.6 & -4.2 & 0.6 \\
\hline
\end{tabular}

